\title{
Comparison of the Effects of Communication and Conflict Resolution Skills Training on Mental Health
}

\author{
Mahin Askari ${ }^{1,2}$, Sidek Mohd Noah ${ }^{1}$, Siti Aishah $\operatorname{Hassan}^{1} \&$ Maznah Baba ${ }^{1}$ \\ ${ }^{1}$ Educational of studies, Univerisity Putra Malaysia, 3400 Serdang, Selangor, Malaysia \\ ${ }^{2}$ Research Center for Social Determinants in Health Promotion Hormozgan, University of Medical Sciences, \\ Bandar Abbas, Iran \\ Correspondence: Mahin Askari, Research Center for Social Determinants in Health Promotion Hormozgan, \\ University of Medical Sciences, Bandar Abbas, Iran. E-mail: mahinask2005@yahoo.com
}

Received: June 1, $2010 \quad$ Accepted: January 10, $2013 \quad$ Online Published: February 21, 2013

doi:10.5539/ijps.v5n1p91 URL: http://dx.doi.org/10.5539/ijps.v5n1p91

\begin{abstract}
This study examined the effects of communication and conflict resolution skills training on mental health among Iranian couples based on the PREPARE/ENRICH program. In this study, mental health was measured by General Health Questionnaires (GHQ28). The study adopted a pre- and post-control group design in emphasizing the effects of communication training and conflict resolution skills on mental health. The participants in this research consisted of couples who were referred to the researcher by counseling center. The referrals were done for about two months in 2009. Their problems included marital problems and marital conflicts, commonly categorized as marital dissatisfaction, which were identified after a formal interview, testing and screening. In order to assign the experimental and control groups, purposive random sampling was employed. One hundred and eight participants comprised of 54 married couples were divided equally between control and experimental groups and the training sessions lasted for eight weeks. In this training program, researchers focused on the dependent variable of mental health, while communication and conflict resolution skills training were the independent variables. Specifically, the t-test statistical analysis was employed to test for the potential significant differences in couples' scores of mental health between (i) the pre- and post-training scores for couples of the experimental group; and (ii) between the post-training scores for the couples of the two groups. The results indicated that teaching communication and conflict resolution skills had significant positive effects on the mental health scores obtained from the studied couples.
\end{abstract}

Keywords: communication, conflict resolution skills, mental health, Iran

\section{Introduction}

This study investigated the effects of communication and conflict resolution skills training on mental health among couples who were facing marital conflicts. A successful marriage would satisfy many mental and physical needs and in case of failure, not only does it cause a breakdown in relationship but also long term mental and emotional suffering to both parties of the marriage. Therefore, a successful marriage rests almost entirely on how well couples emotionally get along (Waite \& Gallagher, 2000). As an unsuccessful marriage would not only lead to a breakdown of relationship, but also result in agony (Carroll \& Doherty, 2003). Poor quality of marriage has been linked even with adverse physical consequences like more severe impairments (Bookwala, 2005; Hawkins \& Booth, 2005; Umberson, Williams, Powers, Liu, \& Needham, 2006). Increased risk of severe mental illness and fatal automobile accidents (Gottman, 1994), physical illness, suicide, violence, homicide (Fischbach \& Herbert, 1997), and functioning difficulties at work (Fosha, 2006) are among the negative effects. Consequently, happiness and fulfilment in marriage play a crucial role in a couple’s life (Yalcin \& Karahan, 2007).

As far as the human relationship is concerned, some marriages can be disappointing, frustrating, and conflicting. Poor communication and conflict may have adverse repercussions on the physical and psychological health of spouses (Strand, 2003; Fincham \& Beach, 1999). These in turn directly lead to changes in depression levels and functional impairment and indirectly to changes in practical impairment via depression (Choi \& Marks, 2008).

Unfortunately nowadays, many marriages provide a disappointing and fragile relationship instead of the most nourishing and enduring one to a great number of people (Olson \& Olson, 2000). This is due to the unresolved 
marital conflicts among couples (Samani, 2008, Zargar \& Doost, 2008, Cramer, 2003, Schneewind, Klaus, \& Gerhard, 2002). Marital conflicts lead to hopelessness, misery, depression, emotional vacuum, loneliness, and infidelity among couples. A study performed by Bakhshi, Asadpour and Khodadadizadeh (2007) concluded that the relationship between poor marital quality and mental health provides evidence for the fact that the more intense the depression among husbands and wives, the less their marital satisfaction. Another study that was conducted in Iran by Memari, Amirmoradi, Khosravi and Godarzi (2006) detected that family violence and marital conflicts were the most important etiological factors of intense depression that would lead to committing suicide among women. An unfriendly and cold atmosphere of life, where parents are unable to understand each other mutually creates perpetual anxiety for the children. Accordingly, loss of efficiency of work or education, tension, nervous behaviour and affliction with physical diseases are the signs which are evident in a divorcing family (Whisman, 2004). It is therefore concluded that greater interpersonal competence, skills and knowledge would benefit marriages nowadays. (Mace, 1975, Mace \& Mace, 1986).

Nevertheless, marital psycho education programs have been found to be useful in enhancing skills and knowledge (Giblin, 1986) and in preventing marital breakdown (Gordon, 1993). Marital education is considered to be a better alternative than marriage therapy, as the latter is associated with fear, stigma, intrusion on privacy and high expenses. Marital education may also encourage couples seek professional help (Larson, 2004). More specifically, arranging marriage education programs as well as practically instructing the couples to communicate more efficiently and resolve their marital conflict more skilfully, which will help them resolve future marital conflicts was regarded as an excellent way to encourage the growth of marital relationship (Fowers \& Blaine, 2001).

Great number of studies has been conducted in Western countries on the effectiveness of marital education programs. Yet, the shortcomings of the experimental studies on the effectiveness of PREPARE/ ENRICH program in Iran remains in the literatures. Moreover, to date, no study has been conducted on the direct effect of ENRICH program on mental health. There has been no report of positive impacts of ENRICH program on mental health issues either. Hence, this study attempts to investigate the effect of a Marriage Enrichment Program on Iranian couples, who are facing marital conflicts. Specifically, it is seeking answers to the question whether communication and conflict resolution skills would help couples cope with or overcome their marital conflicts and improve their mental health. To get the answers of this question, the researcher adopted an intervention program, based on the PREPARE/ENRICH. The PREPARE/ENRICH program is based on the empirical evidence over twenty years research developed by Olson and Olson (2000).

\section{Literature Review}

Poor quality of marriage has been linked even with adverse physical consequences like more severe impairments (Bookwala, 2005; Hawkins \& Booth, 2005; Umberson et. al., 2006). There is a relationship between some mental health problems such as depression and anxiety with marital satisfaction. In other words, the more anxious or depressed either spouse was, the more dissatisfied he or she was with the marriage (Whisman, 2004). Today, the fast and vast change in a social structure has expanded the scope of family and marriage relation development and subsequently has caused an increase in the number of divorces; a reduction in the mean duration of marriage and/or compulsory and imposed life, mental divorce and dissatisfaction of status quo among spouses.

Adam (2004) reports in his study that poor communication, finance, infidelity, substance abuse, physical/emotional/sexual abuse, and inadequate conflict resolution skills are the most common reasons for separation and divorce. A study in the USA has found the lack of commitment (85\%), excessive conflict/arguing (61\%), infidelity (58\%), financial problems (41\%), domestic violence (30\%), family problems (29\%) and religious differences (21\%) to be some of the familiar reasons given for divorce (Adam, 2004). Despite the concerns of people and experts on family matters, many of these relationships can be assumed vulnerable to an eventual break-up from the very beginning. Therefore, it is not surprising that some marriages have led to divorce. It was found that communication and conflict resolution skills are correlated with marital adjustment and divorce rates (Christensen \& Shenk, 1990). In a study by Samani (2008) on the factors related to marital conflicts among married students at Shiraz University in Iran, the researcher revealed that there are six important factors of marital conflict: personality traits, love affection, communication skills, commitment, family background and refinement.

The result of a study on the relationship between marital conflict, children's appraisals of inter-parental conflict and cognitive coping, and their psychopathological symptoms and health in Iran by Gharbaghi and Vafaei (2008) indicated that there is a relationship between marital conflict and children's appraisals of inter-parental conflict 
and cognitive coping. Moreover, they found that marital conflict, children's appraisal and coping can predict their psychopathological symptoms and health, too. In addition, marital conflict and children's appraisals of inter-parental conflict interact can be used to predict their affective behavioural symptom. The result in the form of cognitive-contextual framework, stress-Appraisal-coping theory and developmental systems perspective in child psychopathology, confirm the independent and interactional role of two risk factors, marital conflict children's negative appraisals, in their psychopathological symptoms and health problems.

Marriage provides the fundamental structure for establishing a family relationship and to build the next generation. This is the most important and rudimentary human relationship (Larson \& Holman, 1994). The delineation of influence and power in marriages is of great importance, which couples would do in organizing their relationships (Steil, 2000). As far as human relationship is concerned, some marriages can be the most disappointing, frustrating and conflicting. Poor communication and conflict may have adverse repercussions on physical and psychological health of spouse.

Sharafi (2003) carried out a study on "the relationship between marital communication pattern and mental health in female elementary school teachers and their husbands in Tehran”. The subjects included 200 couples, selected through cluster random sampling. The study utilized the General Health Questionnaire (GHQ) and the marital Communication Pattern Questionnaire (CPQ). The results showed that couples, who used mutual constructive communication patterns, had higher mental health. Couples who used the pattern of mutual avoidance of communication, woman demand/man withdraw, man demand/woman withdraw, and demand/ withdraw, had low mental health. There was a negative and significant correlation between the use of mutual constructive communication patterns and number of children. There was a positive and significant correlation between the rest of patterns and number of children. There was significant correlation between the duration of marital life and communication patterns. There wasn't, either, a significant difference between men and women in questions on communication patterns Questionnaire.

Couples faced with unhappy marriages appear to be deficient in communication skills and are unable to communicate with their partners effectively and such, their marriages are adversely affected. Couples who are not happy are believed not to have the skills and the ability to establish effective communication, which results in their dissatisfaction. Couples who fail to regulate their emotional expressiveness because they do not have the skills to do so often become defensive or withdraw from a conflict situation, a factor that can further add to their dissatisfaction and dissolution. Considering particular styles in resolution was paramount as conflict, management was the core thee in successful marriages (Gottman, 1994). It was observed that a decline in marital satisfaction heralded a series of processes, indicative of deteriorating marriage (Gottman \& Levenson, 1992). According to Whisman (2004), there is a relationship between mental health problem such as depression and anxiety with marital satisfaction. In other words, the more anxious or depressed a spouse was, the more dissatisfied with marriage the spouse was (Whisman, 2004).

Fast changes in social structures have expanded the scope of development for family and marriage relationship, and caused an increase in the number of divorce incidences, a reduction in the mean duration of marriage and/or compulsory and imposed life. Training couples to have better communication skills and solve marital conflicts can serve to strengthen their marital relationship (Fowers \& Blaine, 2001). A study on the effect of communication training on couples' relationship in Isfahan, Iran by Khoshkan, Ahmadi, and Abedi (2008) examined the effects of communication training based on a couple communication program on couple's relationship. The result showed that the couple communication training program improved couple relationships and also the training was effective in relationship factors such as caring for partner, resolving conflict and communication styles. Thus, the need for developing relationship programs for families and conducting researches on marital communication has initiated collaborative efforts from researchers, educators, clinicians, consultants, physicians and students in the United States to develop suitable plans in helping families to have happy and fulfilling marriages.

\section{Methodology}

\subsection{Research Design}

The research design used in this study was pre-test and post-test research design, which encompassed control and experimental groups. Pre-test to post-test designs are research designs widely used in behavioural research, for comparing groups and measuring changes resulting from experimental treatments (Dimitrov \& Rumrill, 2003). It is a classic design that involves the random assignment of subjects to two or more groups. The treatment was applied only on the experimental group. 
Table 1. Randomized subjects, pre-test-post-tests control group design

\begin{tabular}{llll}
\hline Group & Pre-test & Treatment & $\begin{array}{l}\text { 8th week } \\
\text { Post-test }\end{array}$ \\
\hline RE & O1 & $\mathrm{X}$ & $\mathrm{O} 2$ \\
RC & O3 & - & O4 \\
\hline
\end{tabular}

Note: $\mathrm{RE}=$ Experimental group $\mathrm{X}=$ Treatment

$\mathrm{RC}=$ Control group $\quad \mathrm{O}=$ Observation

$\mathrm{R}=$ Randomization

The Os in table 1 signify the observation in pre and post test (Babbie, 2004).

In this design, subjects were divided to experimental and control groups through randomization. Treatment was introduced to the experimental subjects for a specified time, after which the two groups were measured based on the dependent variable. Campbell and Stanley's (1966) Design Number 4 is applied in this study. The administration of both pre-test and post-test to all groups occurs in this design, but the treatment is administered to only the experimental group. The treatments are applied and then the observations of differences of dependent variables are made. Using this design, any observable differences may be attributed to the treatment. In the present study, pre-test and post-test were conducted to determine the effects of communication and conflict resolution skills training on mental health in the treatment group when compared with the control group.

\subsection{Internal and External Validity}

A study with an experimental design needs to consider possible threats that may confound the effects of instruction. This section is concerned with the possible internal and external validity threats related to the current study. Based on Ary et al (2002); Campbell and Stanley (1996), internal validity was the extent of changes observed in a dependent variable that are actually caused by the independent variable(s) in a particular experimental situation (Ary et al., 2002, p. 281). Also, external validity refers to the generalization or representativeness of the findings of the experiment (Cohen, 2000). In this regard, it could be concluded that generalization of the treatment outcomes are restricted by external validity threats.

Table 2 summarizes the internal and external validity threats that can influence the behavior of the dependent variables in an experiment. By employing a control group and randomly assigning for equalization of the groups being compared, all threats affecting internal validity, except mortality, are removed. Consequently, we can make sure that any differences between treatment and control groups are the result of treatment and not something else. In order to ensure that the change in mental health is due to treatment not other factors, the researcher took various steps to control other factors that may influence the result of the study. In order to remind the sessions to the participants, messages were sent to them on the day before each session in an attempt to minimize the attrition of participants in the process of the study.

A briefing session was held at the beginning of the skills training program to ensure that they commit themselves to the 8 weeks of training. Informed consent was obtained from the respondents before the actual training started. The researcher also followed the standardized procedures and techniques of the training program accurately. To minimize the environmental difference between the three subgroups, each of which included 10 couples undergoing treatment and receiving training, the groups were instructed by the same person and the sessions were held in the same place.

Table 2. Internal and external validity

\begin{tabular}{lll}
\hline Sources of Invalidity & Definition & Measure to control possible threats \\
\hline 1. History: & Specific unanticipated events & Random assignment \\
occurring between measurements & Using control group \\
1 and 2. In addition to the & To the knowledge of the researcher \\
& $\begin{array}{l}\text { experimental variable. The } \\
\text { event/s may affect the subject's no study has been conducted in Iran } \\
\text { responses. }\end{array}$ & $\begin{array}{l}\text { in this light. } \\
\text { The duration of the study was not }\end{array}$ \\
\hline
\end{tabular}


2.Maturation

\section{Testing}

4.Statistical Regression

5.Experimental Mortality

6.Selection
Is defined as the growth and maturation of the subjects over time across the experiment (Ary et al., 2002, p. 304).

Is defined as the effect of taking a second test.

Is defined as the selection of groups on the basis of their extreme scores. Usually low or high performance will cause the subjects, on the average, to score closer to the mean on subsequent testing.

Is defined as the loss of respondents from the comparison group more than two months.

The whole period of the study lasted for eight weeks that can result in participants' maturation through channels other than the treatment received from the trainer.

Therefore, the respondents were screened to control for this intervening variable.

Using control group and

Randomization

A pre-test given to the participants to ascertain the homogeneity between the research groups. In addition, the pre-test design's most important feature, provides away to deal with this treat.

The pretest enabled the researcher to check the equivalence of the groups. Thus, if there are no significant difference on the pretest, we can selections could be eliminated as a threat to interval validity of the study.

The selection of couples was not based on extreme scores. Furthermore, EDA measure was checked to ensure the normality of the sample. Also, both experimental and control groups took the same pre-test and post-test, and the study occurred the same time.

To reduce the chances of conflict, an incentive of three possible opportunities was offered : 1. Each participant and spouse could take part in and learn communication and conflict resolution skills at no financial cost.

2. Participants who attended communication and conflict resolution skills' training received a certificate of completion

3. In addition, the research was done with an extensive effort to maintain all participants through the schedules and meeting locations. In this research, the motivation was same for both the treatment and the control groups. Also, researchers added 6 subjects for each group.

Controlled by having couples with similar backgrounds as possible. The 
respondents for the comparison groups.

7.Instrumentation Instrument Decay

or Is defined as an instrument with long scoring procedure which may result in fatigue. Changes in the observers or scorers used may produce changes in the measurement.

8.Interaction of selection Interaction of different extraneous and other threats variables that may be mistaken for the effect of the experimental variable

9. Multiple-treatment interference
Likely to occur whenever multiple treatments are applied to the same responds, because the effect of prior treatment was not usually erasable. couples should have at least secondary education, in order to understand the questionnaire and answer it. In addition, individuals will be 18 years of age or older.

Both ENRICH questionnaire and Mental Health questionnaire have high reliability and validity.

This is controlled as much as possible by ensuring that everything but the treatments was identical. So, a single trainer was used for both groups to ensure uniformity.

Screening and selection was performed to avoid offering the program to couples, who are in concurrent couple's therapy. Hence, they will be eliminated from the study. This was the first study which was done in Bandar abbas. So, there is no probability of multiple treatments at the same time.

\subsection{Population and Sampling}

The participants of this study were couples who were referred to the researchers by counseling centers within a period of two months. Their problems were marital difficulty and marital conflict referred to as marital dissatisfaction. The concept “marital dissatisfaction” was recognized after formalized interviews, testing's and screening. Purposive sampling method was used in the research. The study was conducted on 120 respondents. The sample population included 60 males and 60 females who were selected randomly and divided to two groups of control and experimental.

Table 3. Sample size

\begin{tabular}{lllll}
\hline Group & \multicolumn{3}{c}{ Couple } & Total \\
\cline { 2 - 3 } & Male & Female & \\
\hline Experimental & 30 & 30 & 60 & \\
Control & 30 & 30 & 60 & \\
Total & 60 & 60 & 120 & \\
\hline
\end{tabular}

So each group had 30 males and 30 females. Couples, who were willing to improve their marital relationship, were invited to participate in the program. General Health Questionnaires (GHQ28) was distributed to the couples as pre-test. The researcher assumed that the couples needed to have at least secondary education in order to understand and answer the questionnaires. In addition, they were supposed to be at least 18 years of age and live with their spouse at the time of the investigation.

\subsection{Determining the Sample Size}

The determination of sample population was an essential step in the statistical design of the research. It was important because adequate sample size ensured reliable results of the research. In determining the sample size, the effectiveness of some statistical parameters was noted, including the effect of size index, significant criterion 
and statistical inference power. The researcher's knowledge of one parameter makes it possible to determine the others because of the completely interrelated nature of the parameters. There are some well-known rules to determine each parameter, thus making it possible to determine the power for a study by setting it at .80 (Cohen, 1988). Another common rule related to significant levels, by Cohen (1997) was that in most cases alpha .05 value was acceptable. However, in the case of two-tailed tests and a hypothesis that shows Ma\#Mb, the medium Es, assumed as equal to .05 can be conventionally used (Cohen, 1997). As has already been indicated, the sample size of the two mentioned parameters can be obtained. With the study being two-tailed, 26 was the sample size for each group (Cohen, 1988, p. 55). Basically, whether the study is one or two tailed, is dependent on previous findings. In the absence of any similar study at the local level, the appropriate hypothesis should be two-tailed. For this purpose Table 2.4.1 (Cohen, 1988, p. 55) can be referred to, with regard to the power and effect size. As the study was two-tailed, the sample size was 26 for each group.

\subsection{Screening and Selection}

Screening: Screening and selection was done to avoid offering the program to couples, who were severely distressed or functioning poorly. This was because the program was not designed for individuals, with very severe emotional problems. Screening couples was a three-step process. Before any of the actions above, couples were screened for being 18 years and above, and having at least 5 years of education (include criteria). First, a brief phone interview was conducted followed by a face-to-face interview. The method of the interview was the same as the previous study (Askari et al, 2012) in a way that the twenty-minute phone interview obtained enough information to rule-out couples, who were clearly inappropriate for the group.

The phone interview identified couples, who were not married, physically aggressive to each other, had experiences of extramarital affairs in their history, separated, had substance abuse histories and were in concurrent couple therapy. Generally, couples having ongoing problems with the above "risk" factors were not suitable for the study. In fact, if they answer in the positive direction for more than three of these risk criteria, they were eliminated from the study (exclude criteria).

In order to have a more intimate relationship with the couples and for a better screening, a follow-up face-to-face session was appointed before the start of the program. Some of the symptoms of serious destructive interaction patterns or pathology which were not apparent on phone screening were also taken into consideration over the face-to-face interview. Moreover, other factors that would influence the results including cases that had a history of an extramarital affair or a conflicting interaction style were investigated. The spouses one of whom was not willing to participate in the study were assessed.

Following the interview, the MCQ was used to screen couples with severe conflict. Couples, who scored between 80 to 190 scores, were assigned as suitable couples for the total sample of the research. During the interview, the filled-up consent forms and ground rules for group participation were reviewed. At last, eligible candidates were assigned in two groups randomly. One group was assigned as the experimental group and the other as the wait-list control.

This study only examined two areas of PREPARE/ENRICH program's goals that are as following:

1) Learning useful communication skills, like assertiveness and active Listening.

2) To learn Conflict Resolution Skills using Ten Steps Procedure (Olson, 2004).

Communication skills: Assertiveness and active listening are two specific communication skills emphasized in couple communication skills. These skills assist in increasing the positive cycle of assertiveness and self-confidence and reducing the negative cycle of avoidance and partner dominance for both the individuals and the couple. The counsellor would conclude by giving the couples positive feedback about their assertiveness and active listening skills and how to continue to build up these skills.

Conflict Resolution: This section includes discussions on lack of conflict resolution skills; different conflict resolution styles; constructive and destructive approaches to conflict resolution; and Ten Steps for Resolving Couple Conflicts. In this practice, the counsellor would walk with the couple through the Ten Steps during a feedback session using an issue from one of their growth areas to introduce the process. Then an issue for practicing is chosen by the participants and signed by the researcher as homework that is reviewed the next session. (Olson, 2005).

\subsection{Measurement Instruments}

General Health Questionnaire (GHQ): Mental health was measured with the Persian version of Goldberg's General Health Questionnaire (GHQ-28). The questionnaire development was done by Goldberg and Hillier 
(1979). The GHQ is a self-administered screening questionnaire which diagnoses psychiatric disorders both in primary care and in the community. The GHQ-28 contains 28 items with four sub scales and seven items per subscale. There are four components including somatic symptoms (Items 1-7), anxiety/insomnia (Items 8-14), social dysfunction (Items 15-21), and severe depression (Items 22-28). For the assessment of mental health with GHQ-28, the total of the subscales was used. The GHQ-28 is a self-report questionnaire to measure current mental health. Since its development, the GHQ-28 has been extensively used in Iran. The translated version of the questionnaire, Palahang (1996) recommended a cut off score of 21 women and 22 men.

The General Health Questionnaire (GHQ-28) was translated into the Persian language in 1996 and its validity and reliability have been examined in different settings. Reliability coefficient was calculated at .89. This result demonstrated that the GHQ-28 was internally consistent. Palahang et al. (1996) reported their test-re-test reliability on the Iranian population as $91 \%$. Also, in 2007, a study by Sepahvand et al. in Iran reported $91 \%$ Cronbach alpha coefficient for the whole General Health Questionnaire (GHQ-28). For the four subscales, somatic symptoms, anxiety/insomnia, social dysfunction and severe depression Cronbach alpha coefficient values of $.80, .83, .66$ and .85 respectively were reported. In addition, the scores on the GHQ indicated the mental health status.

Marital Conflict Questionnaire (MCQ): The Marital Conflict Questionnaire (MCQ) screening Questionnaire is a 54-item questionnaire which questions are to measure the husband and wife conflicts In 2009, Marital conflict Questionnaire (MCQ) was developed by Sanai, Barati and Boostanipoor for measuring wife and husband conflicts and some basic aspects. Marital conflict questionnaire is a 54-item questionnaire, which measures husband, and wife conflicts as provided by Dr. Sanai based on his clinical experiences. The questionnaire analyzed eight aspects of marital conflicts including. These areas include decrease in cooperation, sexual relationship, increase in excitement reaction, attracting children's support; individual relationship with relatives, decrease in family relationship with spouse's relatives or friends, dividing financial affairs and decrease in affective communication. Counselors and other clinical experts can use this questionnaire for analyzing husband and wife conflicts.

For each question, there are five items and each has 1 to 5 grades. The maximum grade of the questionnaire was 270 and the minimum was 54. Questions in the subscale include decrease in cooperation $(4,12,18,25,34)$, decrease in sexual relationship questions $(5,13,19,35,40)$, increase in excitement reaction $(6,14,20,27,36,42$, $49,51)$ increase in attracting children's supporting $(9,22,31,38,44$, increase in individual relationship with relatives $(8,15,21,29,37,43)$, decrease in family relationship with spouse's relatives or friends $(1,23,32,46$, $50,53)$, dividing financial affairs, $(2,10,17,24,33,39,48)$ and decrease in affective communication $(3,7,11$, 16, 26, 28, 30, 41, 45, 47, 52, 54).

Cronbach Alpha as an analytic tool was conducted for the whole respondents. The Cronbach's alpha was .96 for the group which included 270 persons. The reliability for the eight subscales are $.81, .61, .73, .33 .86, .89, .71$ and .69 for decreasing of cooperation, decreasing of sexual relationship, increasing of excitement reaction, increasing children's supports, increasing of individual relationship with her/his relatives, decreasing of family relationship with partner' relatives or friends, dividing financial affairs from each other and decreasing of affective communication respectively.

\section{Results and Discussion}

Hypothesis 1: There is significant difference in mental health between pre-test and post-test in the experimental group.

The paired sample t-test was performed to assess the significant difference in mental health between pre-test and post-test of the experimental group, based on achievement. The means are reported in Table 4 below.

Table 4. Pre-test and post-test mental health scores for experimental group

\begin{tabular}{lllllll}
\hline Test & Group & $\mathrm{n}$ & Mean & SD & $\mathrm{t}$ & $\mathrm{p}$ \\
\hline Pre-test & Experimental & 54 & 16.44 & 9.01 & -8.23 & .000 \\
Post-test & & 54 & 7.64 & 4.34 & & \\
\hline
\end{tabular}

$* p<. \overline{05}$ 
The results of the paired sample t-test (Table 4) indicated that the pre-test score for the experimental group is ( $M=16.44, S D=9.01$ ) while the post-test score is $M=7.64, S D=4.34$. According to the data above, the mean score for pre-test of the experimental group is 16.44 compared to the mean score for post-test of the experimental group which is7.64. The mean value of the post-test depicts that couples in the mental health performed better at the post-test level. Therefore, there is a significant difference between the mean scores of the pre-test $(M=16.44$, $S D=9.01)$ and post-test experimental group $(M=7.64, S D=4.34)$ (score for post-test experimental group= 7.64, score for pre-test experimental group $=16.44, P<.05$ ) which suggests that communication and conflict resolution training program led to the promotion of mental health. Based on the data, the result reveals that there is a significant difference in mean value $(t=-8.23, p<.05)$ between pre-test and post-test score in the experimental group. The results reveal that the mean score of mental health in the post-test is less than the mean of the pre-test. Based on the findings, hypothesis 1 is accepted. Therefore, the findings indicate that the program is effective in improving the mental health of Iranian couples.

A successful marriage would enhance mental and physical needs. However, failure it not only causes breakdown in relationships but compounds the problems associated with mental health. Therefore, the establishment of proper relationships enhances the mutual understanding of spouses. In 2006, Khoshkam study on "the effect of communication program on mental health of couple in Isfahan suggested that couple communication program improved mental health. In addition, the program was effective in other mental health issues such as anxiety, social dysfunction and depression. The findings of the inquiry therefore supported the above earlier finding.

Indeed, conflict in married couple relationship was inevitable. It can be either positive or negative. Essentially, the best way to deal with conflict was for partners to learn constructive conflict resolution. Additionally, Kiecott-Glaster and Newton (2001) stated that problematic relationships can have adverse consequences not only for mental health but also on physical health. Moreover, marital conflict was linked with poor general phys-ical health, and also certain illnesses such as heart disease, and chronic pain. Furthermore, Fincham and Beach (1999) study that highlighted a link between marital conflict and suffering from depression, eating disorders, being physically or psychologically abusive.

Research has demonstrated that marital distress and detrimental marital conflict are major risk factors for many sorts of dysfunction and psychopathology (Coie et al., 1993), but constituents of marital success have been related to greater health and longevity (Lillard \& Panis, 1996; Murray, 2000). Following the above harmful results, researchers have revealed that couples faced with unhappy marriages appear to be deficient in communication skills and are unable to communicate with their partners effectively and such, their marriages are adversely affected.

The significant difference in mental health before and after treatment indicated the positive effect of communication and conflict resolution skills training program on the mental health of Iranian couples.

Thus, through communication and conflict resolution skills training conducted in this research, couples learn good communication, constructive communication and conflict management necessary in the resolution of marital problems. Proulx, Helms and Buehler (2007) investigated the link between marital quality and personal well-being utilizing meta-analytic techniques. In a meta-analysis of 93 studies on the quality of marriages and the well-being of individuals, scholars discovered that there is a close link, concurrently and over a period of time, between the quality of a marriage and psychological wellness, leading to the conclusion that a happier marriage is associated with greater personal wellness.

Previous research does indicate that psychologically distressed individuals often withdraw from their relationships because they do not fully recognize their partner's acceptance, love, and commitment (Collins \& Feeney, 2004; Murray et al., 1998).

Hypothesis 2: There is significant difference in mental health between post-test experimental group and control group.

The difference between the mean scores of the post-test experimental group and post-test of the control group is examined by using independent samples t-test. A two -tailed independent-samples $t$-test is calculated to compare the means of the experimental group and the control group. There is a significant difference between the post-test of the experimental and the control groups in terms of mental health $(p<.05)$, which indicates that in the post-test, the former group performed better than the latter group. 
Table 5. Post-test mental health sores for experimental group and control group

\begin{tabular}{lllllll}
\hline Test & Group & $\mathrm{N}$ & $\mathrm{M}$ & $\mathrm{SD}$ & $\mathrm{t}$ & $\mathrm{p}$ \\
\hline Posttest & Experimental & 54 & 7.64 & 4.34 & -7.06 & .000 \\
Post-test & Control & 54 & 16.98 & 8.68 & & \\
\hline$p<.05$ & & & & & &
\end{tabular}

As displayed in Table 5, there is a significant difference between the post-test scores of the experimental and control groups in terms of mental health $(p<.05)$, which indicates that in the post test, the former group has performed better than the latter group. The post-test scores (at the end of the program) for the experimental group in communication and conflict resolution skills have decreased in total compared to the scores of the control group (post-test experimental group $=7.64$, post-test control group=16.98, $p<.05$ ). There is a significant difference between post-test scores on mental health for (treatment group) the experimental group and the control group $(p<.05, \mathrm{df}=77.94)$.

A two -tailed independent-samples $t$-test is calculated to compare the means of the experimental group and the control group. There is a significant difference between post-test scores on mental health for experimental group (treatment group) $(p<0.05, \mathrm{df}=77.94)$. Therefore, the mean post-test score in the experimental group obtained is significantly higher than the mean post-test score in the control group. This indicates that there is a difference between mental health in the post-test experimental group and the control group. Thus, the results indicate there is a significant difference between the treatment and no treatment groups. Therefore, hypothesis 2 is accepted. The mean score shows that the experimental group is generally healthier than the control group. Therefore, there are significant mean differences among these two groups at level of significance .05 with regard to mental health. Based on the result, the hypothesis 2 is accepted in the current research. Therefore, the findings indicate that the program is effective in improving mental health among Iranian couples.

The finding from this hypothesis was consistent with previous research related to mental health in which the mean score of mental health in the experimental group was significantly reduced after treatment. Communication and conflict resolution skills training can be used as a mean of helping couples improve their mental health. Thus, concluded the reduction in the mean score of mental health among Iranian couples in the experimental group was due to the positive effect of these skills training this was because the experimental group underwent treatment hence the significant decrease in their mental health score after eight weeks skills training.

The finding in this section were also supported by Amery (2005) study on the effect of coping skills training on mental health promotion of house wives in Isfahan, Iran. The results indicated that coping skills training was significantly effective on house wives mental health, body signs, anxiety, social performance and depression. In line with these results, coping skills training was significantly effective on mental health and its sub-scales. Additionally, the finding in this section was also supported by sharafi (2003) study on "the relationship between marital communication pattern and mental health in female elementary school teachers and their husband in Tehran”. The results showed that couples, who used the mutual constructive communication patterns, had a higher mental health. Couples who used mutual avoidant communication, woman demand/man withdraw, man demand/woman withdraw, and demand/ withdraw, had a low mental health. The finding of this present study also confirmed the study by Proulx, Helms and Buehler (2007) that found marital quality and psychological well-being were positively related both concurrently and over time such that higher levels of marital quality were associated with greater individual well-being.

The finding was also in consonance with the study on an investigation about the results of relationship status and quality for subjective well-being by Kamp Dush and Amato (2005) explored the association between relationship status, relationship happiness, and a latent measure of subjective well-being. Individuals in unhappy relationships irrespective of relationship status than did individuals in happy relationships reported a higher level of subjective well-being. There, hence, are strong association among the onset and course of a range of mental health problems and destructive marital conflict (Coie et al., 1993; Halford \& Bouma, 1997; Whisman, 2001). Furthermore, the finding in this section was also supported by Fincham and Beach (1999) study that highlighted a link between marital conflict and suffering from depression, eating disorders, being physically or psychologically abusive. In addition to crystal clear supported risks related to marital distress and family fragmentation for adults and children other sequences are distinct as well and could be listed as child behaviour, physical health, economic success and stability (Booth \& Amato, 2001; Doherty et al., 2002; Fincham, 2003; Kiecolt-Glaser et al., 1993; Forthofer et al., 1996). 
Greater levels of marital quality were reported to be linked with higher individual well-being (Proulx \& Helms and Buehler, 2007). Strand (2003) showed that a healthy partnership may contribute to longevity and wives in highly satisfying marriages are less susceptible to cardiovascular disease than their less-satisfied or unmarried peers. Studies concerning relationships between people with mental diseases and their families concluded that relationships are often seriously strained (Uebelacker \& Courtnage, \& Whisman, 2003; Whisman, Uebelacker, \& Weinstock, 2004). In 2007, Proulx et al., claimed that in the literature there are two main perspectives that are linking marital quality and psychological well-being. Likewise, Amato et al., asserted that marital happiness correlates with other indicators of marital quality that inclued marital interaction, marital conflict, marital problems, and divorce proneness (2007). Researches were also carried out on spousal similarity in wellbeing. One of these studies were conducted by Dufouil and Alpervitch (2000) who used the well-being of one spouse. The aim was to predict the others well-being while controlling physical health risk. The results show the well-being of one spouse considerably predicted the well-being of other spouse. Objective measures of physical health finding concordance of blood pressure and chronic conditions among spouses was utilized in recent researches (Stimpson, Peek, \& Markides, 2006).

Waite and Gallagher (2000) have documented literature on the positive impacts of stable and satisfactory marriages on mental, physical, and family health and the personal, financial, and social costs of relationship instability. Moreover, the belief that a satisfying, stable marriage confers advantage not merely to partners but also to their children demonstrated a growing agreement among researchers, theoreticians, and policy makers, that children who are raised in a healthy, happy stable marriage perform more optimally in life (Seefeldt \& Smok, 2004). Likewise, Hawkins and Booth (2005) explored the influences of long-term, poor-quality marriages upon the well-being of couples. The study showed that long-term, that poor-quality marriage has considerable adverse impacts upon general well-being. Hooley (2004) indentified a vicious cycle negative communication that existed in families with a psychotic member. In this situation, family members react negatively to the behaviour of the psychomatic member. This in turn prompts the psychotic family member to react negatively, thus leading to similar reciprocal behaviour by other family members and perpetuating the vicious cycle.

Hooley's (2004) account of the vicious cycle of negative action and reaction between a psychotic member of the family and other family members could confirm the observation that psychotic females tend to experience unsatisfactory relationships. Additionally, Hooley's (2004) account of the vicious tit-for-tat cycle between a psychotic family member and other members of the family is indicative of severe mental illness on the part of the psychotic individual. There are constant exhibitions of hostility and negative communication behaviour by family members towards the affected family member.

\section{Conclusion}

The results reveal that the mean of the post-test was less than the mean of the pre-test which indicates that the program was effective in improving the mental health of Iranian couples. The mean score also showed that the experimental groups were generally better than the control group. Therefore, the results of the study indicated that participating in communication and conflict resolution skills reveal largely positive levels of mental health in the experimental group. Also, it can be concluded from the experimental group study that communication and conflict resolution skills training had positive effect on the mental health of Iranian couples. Therefore, the mean score of mental health for the participants who had undergone the communication and conflict resolution skills training were significantly lower after the treatment was applied.

However, the scenario did not occur in the control group. The decrease in the mean score of mental health was lower among participants who attended communication and conflict resolution skills training. The results of the study revealed that couples who participated in the communication and conflict resolution skills and had completed the skills training had a significant decrease in their mean score of mental health compared to those who had not. Therefore, the research results provided important evidence of the effectiveness of communication and conflict resolution skills training in increasing the mental health of couples. It can be therefore concluded from the experimental group that the communication and conflict resolution skills training had positive effects on the mental health of Iranian couples.

\section{References}

Adams, C. M. (2004). Effects of Problem Specificity, Problem Severity, and Integrative Complexity on Marital Satisfaction. Published master dissertation, University Of Florida.

Amery, N. (2005). The Effect of Coping Skills Training on mental health promotion of Isfahan, House Wifers. Unpublished Thesis. AZ- Zahra university of Iran. 
Ary, R., Jacobs, L. C., \& Razavieh, A. (2002). Introduction to research in education (6th ed.). Orlanda: Harcourt Brace College Publishers.

Askari, M., Sidek, M. N., Siti, A. H., \& Maznah, B. (2012). Comparison the Effects of Communication and Conflict Resolution Skills Training on Marital Satisfaction. International Journal of Psychological Studies, 4(1), 182-195.

Babbie, E. (2004). The practice of social research (10th ed.). Belmont, CA: Wadsworth/Thomson learning.

Bakhshi, H., Asadpour, M., \& Khodadadizadeh, A. (2007). Correlation between Marital Satisfaction and Depression among Couples in Rafsanjan, Iran. The Journal of Qazvin University of Medical Sciences \& Health Services, 2(11), 37-43.

Besharat, M. A., Tashk, A., \& Rezazadeh, M. R. (2006). Explaining the Role of Coping in Marital Satisfaction and Mental Health. Journal of the Iranian Psychology Association, 1(1), 48-56.

Bookwala, J. (2005). The role of marital quality in physical health during the mature years. Journal of Aging and Health, 17, 85-104.

Booth, A., \& Amato, P. R. (2001). Parental pre-divorce relations and offspring post divorce Well-being. Journal of Marriage and Family, 63(1), 197-212.

Campbell, D. T., \& Stanley, J. C. (1966). Experimental and quasi-experimental design for research. Boston: Houghton Mifflin Company.

Carroll, J. S., \& Doherty, W. J. (2003). Evaluating the effectiveness of premarital prevention programs: A meta-analytic review of outcome research. Family Relations, 52, 105-118.

Choi, H., \& Marks, N. (2008). Marital conflict, depressive symptoms, and functional impairment. Journal of Marriage and Family, 70(2), 377-390.

Christensen, A., \& Shenk, J. L. (1990). Communication, conflict, and psychological distance in non- distance in non-distressed, clinical, and divorcing couples. Journal Family Psychology, 4, 63-79.

Cohen, J. (1988). Statistical Power Analysis for the Behavioral Sciences. New Jersey: Lawrence Erlbaum.

Cohen, J. (1997). Statistical power analysis for the behavioral sciences (2nd ed.). Hillsdale, NJ: Erlbaum.

Cohen, L., Manion, L., \& Morrison, K., (2000) Research Methods in Education (5 ${ }^{\text {th }}$ ed), London: RoutledgeFalme

Coie, J., Watt, N., West, S., Hawkins, J., Asarnow, J., Markman, H., Ramey, S., Shure, S., \& Long, B. (1993). The science of prevention: A conceptual framework and some directions for a national research program. American Psychologist, 48, 1013-1022.

Cramer, D. (2003). Facilitativeness, conflict, demand for approval, self-esteem, and satisfaction with romantic relationships. Journal of Psychology, 137(1), 85-99.

De Valut, C., \& Coheen, T. F. (2008). The Marriage and Family Experience: Intimate Relationship (10th ed). United States of America: Thomson Learning, Inc.

Dimitrov, D. M., \& Rumrill, P. D. (2003). Pretest-posttest designs and measurement of change. Work, 20, 159-165.

Dufouil, C., \& Alperovitch, A. (2000). Couple similarities for cognitive functions and psychological health. Journal of Clinical Epidemiology, 53, 589-593.

Fincham, F. D. (2003). Marital conflict: Correlates, structure, and context. Current Directions in Psychological Science, 12, 23-27.

Fincham, F. D., \& Beach, S. R. H. (1999). Conflict in marriage: Implications for working with couples. Annual Review. Psycohology, 50, 47-77.

Fischbach, R. L., \& Herbert, B. (1997). Domestic violence and mental health: Correlates and conundrums within and across cultures. Social Science Medicine, 45, 1161-1176.

Forthofer, M. S., Markman, H. J., Cox, M., Stanley, S. M., \& Kessler, R. C. (1996). Associations between marital distress and work loss in a national sample. Journal of Marriage \& the Family, 58, 597-605.

Fosha, D. (2006). Quantum transformation in trauma and treatment: Traversing the crisis of healing change. Journal of Clinical Psychology, 62, 569-583. 
Fowers, B. J., \& Blaine, J. (2001). The limits of a technical concept of a good marriage: exploring the role of virtue in communication skills. Journal Marital Family Therapy, 27, 327-340.

Gharebaghi, F., \& Vafaei, M. (2008) Conducted a study on marital conflict, children's appraisal of interparental conflict and cognitive coping and their psychopathological symptoms and health in Iran. Journal of Research in Psychological Health, 2(1), 67-78.

Giblin, P. (1986). Research and assessment in marriage and family enrichment: A meta analysis study. Journal of psychotherapy and the family, 2, 79-95.

Goldberg, D. P., \& Hillier, V. (1979). A scaled version of the general health questionnaire. Psychological Medicine, 9, 139-145.

Gordon, L. (1993). Passage to Intimacy. New York: A Fireside Book.

Gottman, J. M., \& Levenson, R. W. (1992). Marital processes predictive of later dissolution: Behavior, physiology and health. Journal of Personality and Social Psychology, 63, 221-233.

Gottman, J. M., (1994). Why marriages succeed or fail. New York: Simon and Schuster.

Halford, W. K., \& Bouma. R. (1997). Individual psychopathology the branch of medicine dealing with the causes and processes of mental disorders. In K. Halford \& H. J. Markman (Eds.), Clinical handbook of marriage and couples intervention (pp. 291-321). New York: Wiley and Sons.

Hawkins, D. N., \& Booth, A. (2005). Unhappily ever after: Effects of long-term, low quality marriages on well-being. Social Forces, 84, 451-471.

Hooley, J. M. (2004). Do psychiatric patients do better clinically if they live with certain kinds of families? Current Direction in Psychological Science, 13, 202-205.

Kamp Dush, C. M., \& Amato, P. R. (2005). Consequences of relationship status and quality for subjective well-being. Journal of Social \& Personal Relationships, 22, 607-627.

Khoshkan, S., Ahmadi, S. A., \& Abedi, M. R. (2008). The Effect of Communication Training on Couples' Relationship in Isfahan, Iran. Journal of Counseling Research and Developments, 6(24), 123-136.

Kiecolt-Glaser, J. K., Loving, T. J., Stowell, J. R., Malarkey, W. B., Lemeshow, S., Dickinson, S. L., \& Glaser, R. (2005). Hostile marital interactions, pro-inflammatory cytokine production, and wound healing. Arch. Gen. Psychiatry, 62, 1377-1384.

Kiecolt-Glaser, J. K., Malarkey, W. B., Chee, M., \& Newton, T. (1993). Negative behavior during marital conflict is associated with immunological down-regulation. Psychosomatic Medicine, 55, 395-340.

Larson, J. H. (2004). Innovations in Marriage Education: Introduction and Challenges. Family Relations, 53, 421-424.

Larson, J. H., \& Holman, T. B. (1994). Predictors of marital quality and stability. Family Relations, 43, 228-237.

Lillard, L. A., \& Panis, C. W. A. (1996), Marital Status and Mortality: The Role of Health, Demography, 33(3), 313-327.

Mace, D. (1975). Marriage enrichment concepts. The Family Coordinator, 24, 171-173.

Mace, D., \& Mace, V. (1986). The history and present status of marriage and family enrichment movement. Journal of psychotherapy and family, 21, 7-17.

Memari, A., Amirmoradi, F., Khosravi, K., \& Godarzi, Z. (2006). Causes of Suicide in Married Women in Iran. The Journal of Faculty of Nursing \& Midwifery, 1(12), 47-53.

Murray, J. E., (2000). Marital Protection and Marital Selection. Evidence from a Historical- Prospective Sample of American Men, Demography, 37, 511-521.

Olson, D. (2005). PREPARE/ENRICH program. Counselor's Manual for PREPARE-ENRICH. (rev. ed.), Minneapolis, MN: PREPARE-ENRICH, Inc.

Olson, D. H. (2004). PREPARE/ENRICH Counselor's Manual. Minneapolis/Life Innovations Inc.

Olson, D., \& Olson, A. (2000). Empowering Couples Building on Your Strengths. Published by life Innovation, Inc. in Minneapolis, Minnesota second Edition.

Palahang, H, Nasr Esfehani, M., Baraheny, M., Shahmohamady, D. (1996).An epidemiological study of mental disorders in Kashan. Journal of psychiatric and psychological research in Iran, 2(4), 19-27. 
Proulx, C. M., Helms, H. M., \& Buehler, C. (2007). Marital quality and personal well-being: A meta-analysis. Journal of Marriage and Family, 69, 576-593.

Samani, S. (2008) The Important Factors of in Marital Conflict Between Married Students in Shiraz University of Iran. Journal of Family Research, 3(3), 657-668.

Sanai, B., \& Alaghband, S., Falahati, S., \& Hooman, A. (2009). Family and Marriage Scales. Tehran, Iran. Besat Publishing.

Schneewind, K., Klaus, A., \& Gerhard, A. (2002). Relationship personality, conflict resolution, and marital satisfaction in the first five years of marriage. Family Relations, 51(1), 63-72.

Seefeldt, K. S., \& Smock, P. (2004). Marriage on the public policy agenda: What do policy makers need to know from research? PSC Research Report, 4, 554.

Sepahvand, T., Guilani, B., \& Zamani, R. (2007). Relationship between Attributional Styles with Stressful Life Events and General Health. Journal of Psychological Research, 9(3 \& 4), 33-46.

Sharafi, A. (2003). The relationship between marital communication pattern and mental health in female elementary school teachers and their husband in Tehran. Unpublished Master Thesis. Tarbiat moallem university of Tehran.

Stanley , S. M. (2007). Assessing couple and marital relationships: Beyond form and toward a deeper knowledge of function. In L. M. Casper \& S. L. Hoffereth (Eds.), Handbook of measurement issues in family research (pp. 85-100).

Steil, J. M. (2000). Contemporary marriage: Still an unequal partnership. In C. Hendrick \& S. S. Hendrick (Eds.), Close relationships: A sourcebook (pp. 125-136). Thousand Oaks, CA: Sage.

Stimpson, J. P., Peek, M. K., \& Markides, K. S. (2006). Depression and mental health among older mexican american spouses. Aging \& Mental Health, 10(4), 386-393.

Strand, E. (2003). Good Marriage, Good Heart. Psychology today, 3021.

Uebelacker, L. A., Courtnage, E. S., \& Whisman, M. A. (2003). Correlates of depression and marital dissatisfaction: Perceptions of marital communication style. Journal of Social and Personal Relationships, 20(6), 757-769.

Umberson, D., Williams, K., Powers, D. A., Liu, H., \& Needham, B. (2006). You make me sick: Marital quality and health over the life course. Journal of Health and Social Behavior, 471-416.

Waite, L., \& Gallagher, M. (2000). The case for marriage. New York: Doubleday.

Whisman, M. A., \& Delinsky, S. S. (2002). Marital satisfaction and an information-processing measure of partner-schemas. Cognitive Therapy and Research, 26, 617-627.

Whisman, M. A., Uebelacker, L. A., \& Weinstock, L. M. (2004). Psychopathology and marital satisfaction: The importance of evaluating both partners. Journal of Consulting and Clinical Psychology, 72(5), 830-838.

Yalcin, B. M., \& Karahan, T. F. (2007). Effects of a Couple Communication Program on Marital Adjustment. JABFM, 20(1).

Zargar, F., \& Doost, H. T. N. (2008). Divorce incidence factors in falavarjan township. Journal of Family Research, 3, 737-749. 